\title{
Becoming Bologna Capable: Strategic Cooperation and Capacity Building in International Offices in Kazakhstani HEIs
}

\author{
Jason Sparks, Adil Ashirbekov, Aisi Li, Lynne Parmenter, \\ Zakir Jumakulov and Aida Sagintayeva
}

\author{
Abbreviations \\ CIP Centre of International Programs \\ CBPAM Centre of the Bologna Process and Academic Mobility (Bologna Centre) \\ HEI Higher education institution \\ IO International Office \\ MoES Ministry of Education and Science of Kazakhstan
}

\section{Introduction}

The aim of this paper is to explore current practices and capacity strengths and challenges in International Offices (IOs) in Kazakhstani higher education institutions (HEIs), as they deal with integration into the Bologna Process and its ramifications for the internationalization of higher education. The paper reports initial findings from the first year of a three-year study on internationalization of higher

J. Sparks · A. Ashirbekov · A. Li · L. Parmenter $(\square) \cdot$ Z. Jumakulov $\cdot$ A. Sagintayeva Graduate School of Education, Nazarbayev University, Astana, Kazakhstan

e-mail: lynne.parmenter@nu.edu.kz

J. Sparks

e-mail: jason.sparks@nu.edu.kz
A. Ashirbekov
e-mail: aashirbekov@nu.edu.kz
A. $\mathrm{Li}$
e-mail: li.aisi@nu.edu.kz
Z. Jumakulov
e-mail: zakir.jumakulov@nu.edu.kz
A. Sagintayeva
e-mail: asagintayeva@nu.edu.kz
(C) The Author(s) 2015

A. Curaj et al. (eds.), The European Higher Education Area,

DOI 10.1007/978-3-319-20877-0_8 
education in Kazakhstan, funded by the Ministry of Education and Science of Kazakhstan (MoES). The focus of the project in the first year was on institutional engagement in internationalization, an area in which IOs and their staff play a key role. It is important to note that this role is an evolving one, being developed in response to the changing international and national contexts, including the Bologna Process. The following three questions are addressed in the paper: (1) What forms of strategic cooperation are considered necessary for effective engagement in achieving Bologna process goals related to internationalization? (2) Do International Offices have the capacity to engage effectively in strategic cooperation for Bologna process goals? (3) What do International Office staff perceive as necessary to develop their professional capacity to achieve these goals? By focusing on Kazakhstan, where little research has been done in this area, we hope that this paper will contribute one response to the appeal made by Deardorff (2012, p. 72), that "as we continue to engage in explorations on rethinking internationalization, it becomes crucial that we seek out and learn from many different perspectives".

\section{Theoretical Perspectives}

The theoretical foundation of this paper is based on three strands of research. The first strand is literature on internationalization of higher education, particularly within the Bologna context. The second strand is higher education change, focusing on the challenges of changing institutional culture within a shifting national landscape of higher education reform. The third strand is capacity building and professional development, as it relates to the work of IO staff engaging with internationalization of higher education as part of the Bologna Process.

\subsection{Internationalization of Higher Education}

The starting point of this paper is the well-known definition proposed by Knight (2004, p. 11), who states that internationalization of higher education is "the process of integrating an international, intercultural or global dimension into the purpose, functions or delivery of post-secondary education". Rather than become fixed on definitions, however, the important point is "the question [of] why and how internationalization can contribute to the improvement of quality of education" (Brandenburg and De Wit 2012, p. 18). This is particularly salient in Kazakhstan, where major reforms to improve the quality of higher education are underway. The process of internationalization can be approached by higher education institutions in many ways, of course, but often begins with a focus on student and possibly faculty mobility in the early stages, together with the forming of international partnerships and networks (Knight 2013), followed by alignment of structures and policies to make higher education more internationally translatable. Engagement in 
the Bologna process is key to facilitating these three aspects. At the institutional level, this early stage is often followed by a focus on internationalization at home, which centres on internationalization of the curriculum and integration of international students (Jones and Brown 2007; Leask 2013). Both these aspects are complex and require significant commitment and resources by many different parts of the institution. Attention to internationalization at home, in turn, leads to a greater focus on quality of internationalization, and on the embedding of internationalization throughout the institution, although for many institutions, this stage remains a mission statement aspiration rather than a reality (Jones and de Wit 2012). It is at this stage, if achieved, that internationalization makes the shift "from the margins of higher education to its core" (Jones and de Wit 2012, p. 36). For this paper, these various stages and aspects of internationalization of higher education provide a backdrop for discussion of the case in universities in Kazakhstan. These are not the only important aspects of internationalization of higher education, clearly, but other aspects are less relevant to the situation in Kazakhstan at this moment in time. An important point to note is that academic mobility of both students and staff is well funded by the government in Kazakhstan, and internationalization does not have the commercial, market-driven priorities that dominate in some other countries.

\subsection{Institutional Change}

The second strand of relevant research is institutional change in higher education. The national landscape of higher education is in a process of rapid reform in Kazakhstan as universities become more autonomous, meaning that institutional change is forced, rather than optional. However, responses to national and institutional change vary across universities, and are partly dependent on institutional culture. As Lumby (2012, p. 581) states, highlighting the multiple and diverse cultures that exist in any HEI, "culture is a fundamental shaping and disciplinary force on which organizations depend". Lumby goes on to emphasize that "while organizational cultures cannot be controlled, they can be influenced to some degree and... deciding on the direction of influence is a key moral challenge for leaders" (2012, p. 586). Within the higher education context, where leadership tends to be distributed, recent studies have highlighted the leadership role of professionals and administrative staff in collaborative leadership of higher education changes (e.g. Jones and de Wit 2012). This leadership role is relevant to our study of IO directors and staff in Kazakhstan. Another perspective that is potentially valuable in considering the role of IO staff in the realm of strategic cooperation in the Bologna Process is the role of social networks in organizational change within and across institutions. As Kezar (2014, p. 95) points out in an article advocating the use of social network analysis in conjunction with organizational theory to study higher education change processes, "informal networks of relationships have a significant impact on whether individuals decide to engage in change or reform behaviour". 
Closer attention to social networks could yield insights into why and how certain reforms, including Bologna Process related reforms, are successful or unsuccessful within institutions or across systems.

\subsection{Capacity Building and Professional Development}

The third strand is capacity building and professional development, with a specific focus on the work of IO staff in HEIs. Although capacity building and professional development are occasionally recognized in relation to faculty development (e.g. Jiang and Carpenter 2014), there is very little international research on the existing capacity and perceived professional development needs of IO staff, with greater attention paid to barriers caused by lack of financial or strategic resources (e.g. Koehn et al. 2011). This may partly be due to the fact that much of the literature on internationalization of higher education is produced in countries which have traditionally been receivers of internationally mobile students, where there is considerable experience of international engagement, and where language may not be a barrier to international engagement. In many countries, however, collective experience of international engagement is limited at institutional level, and lack of proficiency in English may be a significant barrier to effective engagement in internationalization. Some of the issues are highlighted by Telegina and Schwengel (2012, p. 46), in an article about the Bologna process in Russia:

\footnotetext{
...poor resources for international activities, understaffed international offices, shortage of competent and motivated personnel because of low salaries do not allow institutions to actively participate in international cooperation. The knowledge of foreign languages, the inter-cultural experience and the level of understanding of the Bologna principles and practices in many universities are still rather limited.
}

In dealing with problems such as these, questions of capacity building and professional development demand attention, within a wider context of reflection on what kinds of capacities are necessary to engage in internationalization for what purposes and for whose ends. Whatever the requirements for professional development for the Bologna Process in any given context, "the need to equip staff at all levels with the awareness and skills necessary for effective internationalization" (Taylor 2010, p. 104) is emerging as a priority, particularly given that "internationalization has become a major force for change in how the modern university is managed" (Taylor 2010, p. 107).

Together, these three strands of research provide a foundation for considering the perspectives of IO staff in Kazakhstan on strategic cooperation and capacity, as they engage in the internationalization of higher education within a rapidly changing national and international context of higher education, where universities are working with increased levels of autonomy and are engaging in the Bologna Process. Before introducing data results, a brief description of the national context of internationalization of higher education in Kazakhstan is necessary to understand the full picture. 


\section{Kazakhstan Context}

In the academic year 2011/2012, there were 146 HEIs in Kazakhstan, which has a population of approximately 17 million people. There are around 610,000 students studying in HEIs, of whom 320,000 study in state HEIs and 290,000 in private institutions (Education, Audiovisual and Culture Executive Agency 2012).

Since its independence in 1991, reforms have dominated Kazakhstan's higher education system, with internationalization comprising a vital part of this process. By the end of 2011, the number of international agreements signed by the MoES with other countries in the field of education and science reached 124, and the overall number of agreements signed by higher education institutions was around 8000 (MoES, Ministry of Education and Science of the Republic of Kazakhstan 2012).

In 2010, Kazakhstan became a full member of the Bologna Process. Since then, the Bologna Process has been a driving force of internationalization of the Kazakhstani higher education system. To some extent, as in Russia and some other post-Soviet countries, the Bologna Process has become "both a symbol and an embodiment of internationalization for ... higher education" (Telegina and Schwengel 2012, p. 45).

Recognizing the necessity to promote and support internationalization of higher education institutions, the Kazakhstani government began to lay the legal framework with Laws on Education passed in 2007, granting Kazakhstani HEIs the right to establish direct cooperation with foreign institutions (MoES, Ministry of Education and Science of the Republic of Kazakhstan 2007a). Shortly afterwards, in order to facilitate the internationalization of HEIs, the MoES announced the decree on approval of Rules for International Cooperation Realized by Educational Organizations (hereinafter Order No. 661) (MoES, Ministry of Education and Science of the Republic of Kazakhstan 2007b). These laws and regulations act as the legal basis of IOs, regulating their responsibilities, mission and structure. Order No. 661 stipulates that the main tasks of IOs include establishing and maintaining international partnerships, intelligence research on national and international practices of internationalization, and providing logistic support to inbound and outbound academic mobility. IOs have different titles across HEIs in Kazakhstan, and are part of different administrative departments within the institution, most commonly the Department of Strategic Development or the Department of Science and Research.

As early as 2003, a handful of Kazakhstani HEIs signed the Magna Charta Universitatum. This gradually spread among HEIs and the Kazakhstani government felt the need to create a legal framework for it, thus triggering Kazakhstan's journey into the Bologna Process. In 2010, Kazakhstan became a full member of the Bologna Process, and its commitment to reform its HEIs according to the Bologna Process is reflected in the State Program of Education Development for 2011-2020, which stipulates "integration into the European Higher Education Space through bringing the content and structure of higher education into compliance with the 
Bologna Process" (The Republic of Kazakhstan 2010). From this time, the requirement to comply with the Bologna Process has been stimulating reforms at institutional level.

Student and faculty mobility lies at the centre of reforms according to the Bologna Process principles. The government has issued the Strategy for Academic Mobility in the Republic of Kazakhstan for 2012-2020, which sets a national target of $20 \%$ of students being mobile by 2020 (MoES, Ministry of Education and Science of the Republic of Kazakhstan 2012). This ambition is financially supported by the country's Academic Mobility Scholarships, currently managed by individual HEIs (Engberg et al. 2014, p. 28). Additionally, the well-established Bolashak Scholarships, managed by the Centre of International Programs (CIP), also provide incentives for students and faculty to study abroad. To coordinate the implementation of the strategy for academic mobility, MoES established the Centre of the Bologna Process and Academic Mobility (CBPAM, commonly referred to as the Bologna Centre) in 2012. It functions as a subordinate organization of the MoES to facilitate the proper implementation of Bologna Process principles at the national and institutional levels. CBPAM provides guidance to HEIs on the implementation of Bologna Process principles and collects data from HEIs to monitor the progress of Bologna-compliant reforms.

It is not compulsory for HEIs to have an office or person dedicated to the implementation of the Bologna Process, and HEIs can decide who is responsible for overseeing the implementation of the Bologna Process. Our survey of the websites of national/state universities show that some HEIs have a unit in charge of the Bologna Process, some assign the responsibilities to the IOs, some have both an IO and an office of the Bologna Process, while others delegate the task to various departments.

Examination of the mission statements and development strategies of the aforementioned HEIs confirms that internationalization and the Bologna Process are an integral part of these documents, although they are phrased in different ways. In general, from the 26 institutional documents (strategic plans, mission statements, and related online materials) analyzed, goals for internationalization and the Bologna Process fell into four categories:

- to provide education according to international standards

- to be incorporated into global or European Higher Education Area education space

- to implement reforms according to the Bologna Process principles

- to produce graduates who are competitive in the global job market

According to the institutional strategies and action plans collected, Kazakhstani IOs have varied roles and influence depending on the institutions. Usually, they cooperate with other departments to achieve institutional goals.

The review of the historical development of IOs and the Bologna Process in Kazakhstan shows that IOs already operated for some time prior to the introduction of the Bologna Process. The knowledge, skills and experience IOs accumulated over the years can be useful to assist the embedding of Bologna Process parameters 
at institutional level. Institutional documents suggest that IOs are cooperating with other academic and administrative departments in achieving the Bologna goals.

\section{Methodology}

Mixed methods were used in this study to explore the official discourse of the significance of IOs in the internationalization process of higher education in Kazakhstan, as well as to examine the reality of IOs' operations at institutional level, in particular, their strategic cooperation with different agencies at various levels to implement Bologna Process principles. Multiple sources, including government policy, institutional strategic documents, interviews and a national survey provided rich data. The questions that guided the collection and analysis of data were:

- What forms of strategic cooperation are considered necessary for effective engagement in achieving Bologna process goals related to internationalization?

- Do International Offices have the capacity to engage effectively in strategic cooperation for Bologna process goals?

- What do International Office staff perceive as necessary to develop their professional capacity to achieve these goals?

Government decrees and action plans issued by the MoES were analyzed, as were reports published by CBPAM, and mission statements and development strategies of 27 out of 57 national/state universities. Our understanding of how national policies are interpreted and implemented at institutional level was deepened through a national survey, a roundtable discussion and interviews, all of which involved directors and staff members of IOs. In this preliminary research, 48 responses were received from the national survey. In-depth interviews were then conducted with three university International Officers and two senior leaders at CBPAM.

This combination of document analysis, survey and interviews at various levels provided material to explore international, national, and intra-institutional strategic cooperation between IOs and other agencies.

\section{Results}

This section is organized around the three research questions guiding this inquiry, and focuses on the following topics: (1) forms of strategic cooperation considered necessary for effective engagement in achieving Bologna process goals; (2) perceived IO capacity to engage effectively in strategic cooperation for Bologna Process goals; and (3) perceived IO professional development needs for Bologna Process work. 


\subsection{What Forms of Strategic Cooperation Are Considered Necessary for Effective Engagement in Achieving Bologna Process Goals?}

Three dimensions of strategic cooperation required for Kazakhstani university IOs to achieve national and institutional goals for internationalization emerged from data analysis: international; national; and intra-institutional.

\subsubsection{International Dimension}

One form of strategic cooperation identified was the development of links between universities internationally (partnerships, strategic relationships, international cooperation, and joint projects). Combined, these forms of international linkage between institutions were identified in the questionnaire as areas of success for 19 of 41 International Officers asked to "describe a specific example of one activity that has been successful in your university". Given this perceived success, it seems fair to assume they are considered key forms of engagement necessary for achieving national and institutional Bologna Process internationalization goals.

\subsubsection{National Dimension}

National level strategic cooperation also emerged as important in the study, particularly with the MoES. Results from the survey of 48 university International Officers indicates that such support is unevenly perceived across Kazakhstan. International Officers were asked, "To what extent do you think the Ministry of Education and Science in Kazakhstan supports internationalization in your institution?" (Fig. 1).

While $79 \%$ (37 of 47) respondents reported MoES support either "to some extent" or "very much," interestingly, $21 \%$ (10 of the 47), reported "not at all" or "very little."

A key aspect of internationalization in HEIs in Kazakhstan relates to engagement with the CBPAM. ${ }^{1}$ One of the interviewees formulates what seems to be a broader sentiment among the sample, namely that national policy for the Bologna Process is a very centralized strategy:

The policy for Bologna is very centralized. The national Bologna Centre dictates our policy, and the universities only act as implementers. Universities do not act as policy makers. They don't produce their own strategy of the Bologna Process. Someone dictates to you, [and] you just do what they want you to do. And you need to send these reports back

\footnotetext{
${ }^{1}$ The interviewees often referred to CBPAM as "the national Bologna Centre" or "the Bologna Centre".
} 

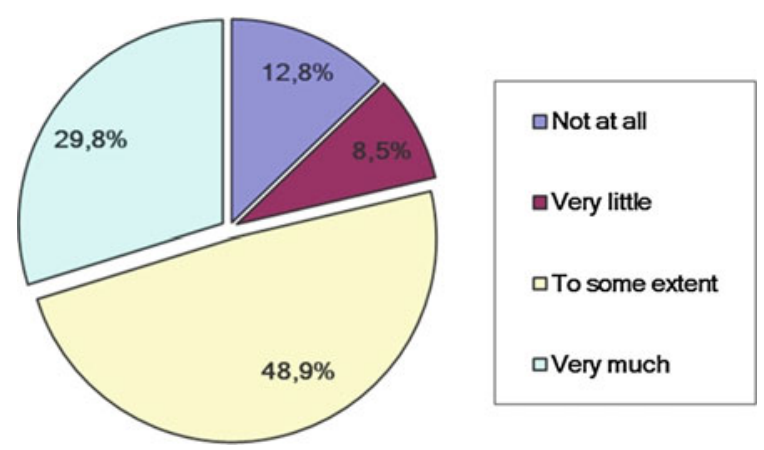

Fig. 1 Q3. To what extent do you think the Ministry of Education and Science in Kazakhstan supports internationalization in your institution?

to them. Every three months, the Bologna Centre sends these questions to every university and you have to fill in these numbers.

The work of the CBPAM appears, therefore, to be very clearly delineated for International Officers, suggesting more compliance than creativity or collaboration. This theme is elaborated by another International Officer as a division of labour between the IO and the Bologna Office (in those situations where institutions have both offices) on the main area of their work, student mobility: "Academic mobility is the work of the Bologna Office. They do the paperwork. The International Office is responsible for establishing partnerships. The Bologna Office works out the details."

This International Officer describes a situation in which Bologna Office staff within universities work directly with individual university administrative departments, such as Human Resources and Finance. In this context, not only is the IO bypassed by the Bologna Office, but the IO does not interact much with administrative departments: "The IO does not interact frequently with administrative departments, but the BP Office does." Understanding relations between IOs and Bologna Offices in universities that have both seems to be important to understanding internationalization of higher education in Kazakhstan.

\subsubsection{Intra-institutional Dimension}

Within institutions, there appears to be strong strategic cooperation between International Officers and senior leadership. The key indicator of this strength is that International Officers report participation in the development of internationalization strategy with senior leadership. As one International Officer described in an interview, "The IO makes its part of the whole strategy of the university and other departments do the same".

As the figure below shows, $90 \%$ of respondents reported they "strongly agree" or "agree" that their IOs are able to influence strategic decision-making for 
Fig. 2 Q13. The International Office is able to influence strategic decision-making regarding internationalization in our university

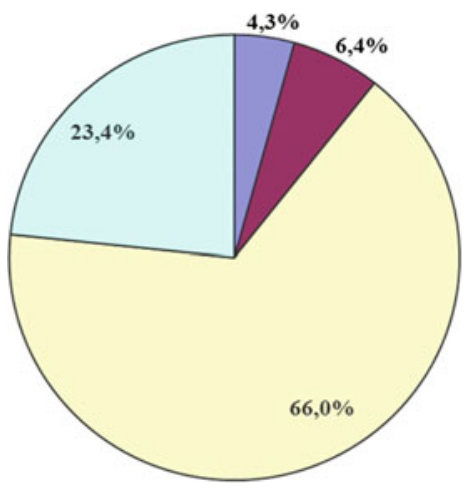

口Strongly disagree

Disagree

$\square$ Agree

$\square$ Strongly agree

Fig. 3 Q14 The senior leaders of our university are supportive of the activities of the International Office

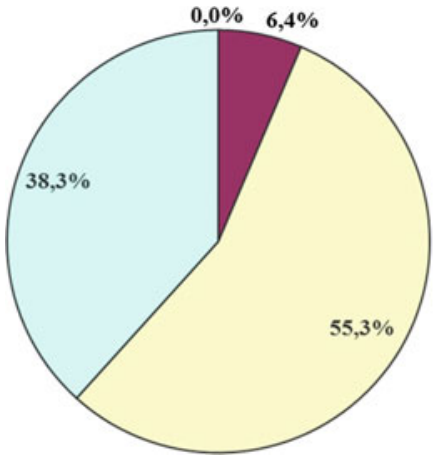

$\square$ Strongly disagree

- Disagree

$\square$ Agree

$\square$ Strongly agree

internationalization in the university (Fig. 2). This important strategic cooperation between International Officers and their senior leadership suggests a strong organizational foundation to build the capacity and role of IOs in further implementation of institutional and national goals for internationalization. It should be noted that we did not ask whether they believed they should have such a role, which limits any interpretation of whether an increased role in strategic planning is desired.

Similarly, when asked whether they feel senior leaders of their universities were supportive of the activities in their IOs, $94 \%$ of respondents stated they agreed they were supported, while only $6 \%$ disagreed (Fig. 3).

These results raise a further set of questions to be explored in the next round of inquiry: (1) What type of influence do International Officers seek to have with senior leaders in strategic decision-making processes? (2) What would facilitate that influence? (3) What forms of senior leadership support are currently being experienced by International Officers? (4) Which forms of senior leadership support would be most helpful for International Officers?

Another area of intra-institutional strength in developing strategic cooperation reported by respondents relates to the importance of all stakeholders understanding institutional strategy (Hayward et al. 2003). When asked whether they agreed that 
the strategic goals of internationalization were understood by all university administrative staff, $13 \%$ (6 of 47 respondents) stated they "strongly agree," $70 \%$ (33 respondents) said "agree," $15 \%$ (7 respondents) stated "disagree," and $2 \%$ (1 respondent) said "strongly disagree."

\subsection{Do International Offices Have the Capacity to Engage Effectively in Strategic Cooperation for Bologna Process Goals?}

In terms of capacity to achieve Bologna Process goals, findings show that International Officers perceive both strength and challenge. Strengths include reported influence on strategic decision-making and language capacity. Challenges include staffing, language barriers, and ambiguous division of labour between the institutional Bologna Offices and IOs.

Strengths: Influence on Strategic Decision-Making

One strength for International Officers was already described above in the discussion of Key Question 1 on intra-institutional strategic cooperation. With $90 \%$ of respondents agreeing that their $\mathrm{IO}$ is able to influence strategic decision-making for internationalization in the university, there is clear potential capacity to engage effectively within the institution to achieve Bologna Process goals. As one International Officer stated in an interview: "The International Office participates in strategic development. The International Office makes its part of the whole university strategy."

Strengths: Language Capacity

Another capacity to engage in strategic internationalization cooperation is language capacity. As one International Officer described, "English is very important in international partnerships. The [university] departments will go to the IO for assistance." Language capacity also emerged as important in responses to an open-ended question asking what the main tasks completed by International Officers were during the past week. In 39 responses, translation of texts was cited by 12 respondents. Furthermore, in every single response there were the inevitable, but still important to note, references to multiple forms of communication with international partners, including meeting foreign delegations, correspondence, video conference and so on. These tasks require more than just linguistic capacity, of course, involving as they do capacity to establish relationships with foreign universities, facility in working with myriad documents in diverse languages, and understanding of a range of issues such as accreditation and multiple programs - as well as the multiple regulations associated with each.

Challenges: Staffing

One key challenge in IO capacity to work towards achieving institutional goals for internationalization was staffing. When asked what needs to be improved to help IO staff meet the challenges of their jobs, one interviewee exclaimed: "Staff! It has 
to be expanded. There were 4 and now 3." However, this is problematic given a range of challenges in finding and retaining qualified employees: "They need to have good English, proper background and experience. It's difficult to find the right person. Salary is a problem. I had problem finding a senior manager. The HR, who don't speak English, check their psychological background, but not English. When I interviewed them, their English was not what I expected it to be. People with the right credentials don't apply for this job. We offer [the post-holders] $20 \%$ off at our clinic of the university, and the union also offers some discounts and free stuff. There are bonuses but not the salary. We are competing with other sectors [of the job market] for the right person. Universities are sometimes losing. When they are trained up by the universities, they move to other sectors for higher salaries."

This challenge of finding and retaining staff is exacerbated, according to this participant, because of the high job qualifications: "It's the same salary across the departments, but we have higher credentials. For example, we need to speak three languages, Russian, Kazakh and English! Same salary, but higher credentials!"

Challenges: Language Barrier

The language capacity described above as a strength was also highlighted in another interview as a challenge: "The first major problem is [the] language barrier. It may sound really ironic, but there are still, you know, more rural areas, with universities where International Officers cannot speak English."

In many ways, language barriers to the work of an IO in Kazakhstan might be understandable and even predictable; nonetheless, given the emphasis placed on this issue in our findings, it would be worth looking more deeply into this issue in order to understand the nature of the challenge and explore ways institutions might address it.

\section{Challenges: Division of Labour Between Bologna Office and IOs}

One potential challenge for IO capacity is suggested in interviews of Internationalization Officers who describe a division of labour between the Bologna Office, or those responsible for administrating Bologna Process work in institutions, and the IOs. More information is required on the specific ways Bologna Offices work within institutions, and on the relationship of institutional Bologna Process work and the IO. However, this issue highlights a possible need for training and other support for International Officers to facilitate successful institutional Bologna Process work, particularly given the possibility that the dimensions of institutional internationalization, Bologna Process work and the other IO work may be integrated into one office in the future. System-wide, this division of labour and function is complicated by the fact that, as described above, the relationship of the CBPAM to universities is not uniform. Some institutions have a dedicated Bologna Office on campus, some do not, but all universities are mandated to have a unit that functions as an IO, even though it may have a different name. The point here is that there seems to be a separation between the IOs and the Bologna Offices, even as they work toward the same goals in the same activities. This separation is described by one International Officer in an interview: "It's divided. Each of us does our work." But for this participant, when asked whether the work of the International Office and the institutional work done by the Bologna Office should be combined in 
one office, she replied: "Yes, definitely. [Just like] our partner universities [who] would have a vice rector in international cooperation. There must be one person to manage this step and make sure that the university people know who to address. Mobility and exchange programs have to be in one person's hands."

Implicit here is a set of challenges related to what appears to be an artificial division of responsibilities across two institutions (the university and the CBPAM) and often within one institution (IO and Bologna Office) centred on one set of activities: academic mobility. (This participant described the emphasis on academic mobility this way: "As for now, we understand the Bologna Process as only academic mobility. Most universities do the same.") At issue is whether IO staff have the capacity to work across this division of labour to achieve institutional goals for one institutional strategic plan. This capacity challenge is suggested by one International Officer interviewed who described her view that her IO staff should be made aware of "Bologna Process related laws and articles", but they do not receive any information or training either at her institution or through the CBPAM: "I would introduce the staff to the Bologna Process-related laws and articles. They need to know. It's relevant to our work. But the university leadership does not initiate this training."

When asked whether her staff were ever invited to the CBPAM for training, she replied, "No. The IO is not invited."

At this stage, this challenge is merely suggested in the interviews and needs to be explored in greater depth as an issue that may become increasingly significant in the future, when the planned closure of the CBPAM devolves Bologna-related work to other national institutions in 2015. This could have a significant impact on the nature of IO work, and capacity development may emerge as important.

\subsection{What Do International Office Staff Perceive as Necessary to Develop Their Professional Capacity to Achieve These Goals?}

International Officers were asked in the survey what forms of professional development they considered should be provided for them at the national level. Responses are ranked in Table 1.

While the top two answers are predictable, to a certain extent, it would be valuable to explore in greater depth what sort of seminars or workshops abroad would be useful and why, and what sort of information International Officers feel is required and why.

Of particular interest is enthusiasm for the creation of a national association of University International Officers, ranked third among the five at $54 \%$. An important dimension of our three-year research project into internationalization of higher education in Kazakhstan is facilitating precisely such associations, and the need for such a network is alluded to by an International Officer during an interview: "The 
Table 1 What kind of activities, opportunities or resources should be available for International Officers?

\begin{tabular}{l|l|l|l}
\hline Rank & $\begin{array}{l}\text { Number of times } \\
\text { item selected } \mathrm{N}=41\end{array}$ & $\begin{array}{l}\text { Percentage of } \\
\text { respondents }(\%)\end{array}$ & Answer choices \\
\hline 1 & 39 & 95 & $\begin{array}{l}\text { Participation in seminars/workshops } \\
\text { abroad }\end{array}$ \\
\hline 2 & 27 & 66 & $\begin{array}{l}\text { Information resources- } \\
\text { guidelines/recommendations }\end{array}$ \\
\hline 3 & 22 & 54 & $\begin{array}{l}\text { Creation of a national association of } \\
\text { University International Officers }\end{array}$ \\
\hline 4 & 20 & 49 & $\begin{array}{l}\text { Professional development } \\
\text { (seminars/workshops) in Kazakhstan }\end{array}$ \\
\hline 5 & 15 & 36 & Legal consultancy \\
\hline
\end{tabular}

International Office rarely directly communicates with the International Offices in other universities. [Although] it happened before that when a university was going to set up an International Office, they called me and asked for my experience. It's more about experience sharing."

One important professional capacity resource for International Officers was already described above with regard to (lack of) training and information about the Bologna Process. Another interview participant described professional development opportunities in her institution as based on her Rector's "strategic vision about staff development, especially to meet [an] international level [of quality]." She elaborated: "I have attended a lot of trainings, like change management, human resources, coaching and communication. They were paid and organized by the university. The instructors will come to the university. We don't even have to leave the university. Staff can initiate trainings. There's a department responsible for this. I could have gone on professional development training programs on the Bolashak Scholarships. Almost 50 staff from various levels of our university went on it.”

This description of professional capacity development opportunities at one institution would seem to point to the way for others seeking to develop IO staff capacity.

\section{Discussion}

The research reported here represents the first round of data collection, intended to highlight issues of importance that will be explored in greater depth in ongoing research. It is important to emphasize that this research takes place at a time when national policy is shifting the institutional architecture for Bologna Process administration and other internationalization policies. 


\subsection{The Potential for IO Leadership for Comprehensive Internationalization}

Our results show that International Officers in Kazakhstan overwhelmingly report they are able to influence strategic decision-making for internationalization in their institutions. This influence suggests a strong cooperative relationship with senior management. But what role might the IOs have working more comprehensively across the institution, in ways described by Heyl and Tullbane (2012, p. 115) as working "across every facet of the institution" and "crossing organizational boundaries and entering fiefdoms of other power brokers (deans and other senior administrators)"? Extending the point a little further, Kezar's social network analysis may be valuable for exploring in more depth the ways the "informal networks of relationships" of International Officers can be leveraged for institutional change (2014, p. 95). Potential and need for IO leadership for comprehensive internationalization (Hudzik 2011) may increase if the role for IOs in Bologna Process work intensifies in Kazakhstan.

\subsection{The Need to Increase IO Capacity for Bologna Process in Times of Institutional Change}

As part of recent national policy for optimizing and rationalizing Kazakhstani government institutions, the roles and functions of state institutions are in a process of change, and this extends to those institutions related to internationalization of higher education: The CBPAM; the CIP; and the National Academy of Education. For example, the current CBPAM work on academic mobility scholarships is reportedly to devolve to the CIP (Engberg et al. 2014). Moreover, there is discussion of shifting the CBPAM responsibility for verifying overseas diplomas to the National Academy of Education (personal communication 29 August 2014). These institutional changes, and others that may become manifest through 2015, will certainly have implications for IOs in their work within institutions and with national-level institutions.

These institutional shifts provide strong argument for greater IO capacity for Bologna-related work. One mitigating factor in developing this capacity seems to be the current division of labour between the IO and the Bologna Office working within institutions. An important first step in strengthening IO capacity for the Bologna Process was cited by the IO interviewed above, who sought, but could not provide her staff with, Bologna Process training and information. This IO's perspective is consistent with that of Telegina and Schwengel, who cited among challenges to implementing Bologna Process goals the "level of understanding of the Bologna principles and practices" (2012, p. 46). As the demands on IOs for Bologna-related work increase, Kazakhstani officials and institutional leaders will need to explicitly address the professional development needs of IOs for that work. 


\subsection{Making Professional Development for International Office Staff a Priority}

Taylor states that there is "a growing recognition of the need to equip staff at all levels with the awareness and skills necessary for effective internationalization" (2010, p. 104). Given the importance of IOs in internationalizing institutions, and the shifting institutional terrain for internationalization in Kazakhstan described above, it seems clear that professional development for IO staff needs to be a priority. While it would be wrong to assume that the changing work of Kazakhstani IOs will follow the same path as other countries, it is interesting to consider the need for and potential of professional development for IOs in Kazakhstan to enable them to undertake some of the roles adopted by senior international officers in other countries, such as "assessing campus internationalization" and "understanding and applying the trends in internationalization" (Heyl and Tullbane 2012, p. 125), "tak [ing] on even more active roles in promoting and coordinating international research and development activity" (Koehn et al. 2011, p. 344), "successfully spreading an internationalization ethos throughout the fabric of the university" (Heyl and Tullbane 2012, p. 127), and "becom[ing] repositories for research and expertise on maximizing the effectiveness of international collaboration" (Koehn et al. 2011, pp. 344-345).

These signal possible directions for the work of Kazakhstani IOs as higher education reforms and Bologna Process changes redefine their work. Whatever the actual nature of the changes in Kazakhstani IO work, IO capacity for success in this changing higher educational context seems premised in national-level officials and institutional leaders making a priority of "professional development and support for the administration of international education" (de Wit, as cited in Heyl and Tullbane 2012, p. 119).

\section{Conclusion}

Overall, there are three points from this paper that we would like to highlight in conclusion. The first is that the drivers of internationalization in Kazakhstan at present are not commercial. Mobility is well funded by central government, and universities do not engage in internationalization activities mainly for financial reasons. Different drivers result in different outcomes, and this is an interesting area for further study.

The second point is that HEIs themselves are proactive in engaging in internationalization. Engagement with the Bologna Process and academic mobility in Kazakhstan originated in universities, rather than as a top-down initiative, and this is important to take into consideration when considering leadership potential for strategic cooperation within universities. While the MoES and the CBPAM provide legal, financial and structural support for engagement in the Bologna Process and 
associated activities, the onus remains on universities to engage in internationalization. The results of our survey and interviews show that International Officers already work closely with senior leadership and academic departments within their institutions, and there is considerable scope for them to take a wider leadership role in strategic cooperation at international, national and intra-institutional levels, especially as universities become more autonomous.

The third point is the recognized and urgent need among IO staff for capacity building through professional development. If IO staff in Kazakhstan were enabled to engage in the professional development they perceive as necessary, it seems likely that they would be able to take on the wider engagement of internationalization of higher education, beyond management of academic mobility.

Jones and de Wit (2012, p. 46) state that "the voices of countries who have come onto the scene more recently should be heard as offering new perspectives and dimensions to the existing landscape of international education". We hope that this paper gives voice to perspectives from Kazakhstan, as it embarks on its Bologna journey. With its rich multicultural heritage, at the crossroads of Europe and Asia, Kazakhstan's internationalization journey may not follow the same path as other European countries, but if the potential of IO staff can be realized and the focus of engagement in internationalization can remain improvement of the quality of education and research, the journey promises to be an interesting one.

Open Access This chapter is distributed under the terms of the Creative Commons Attribution Noncommercial License, which permits any noncommercial use, distribution, and reproduction in any medium, provided the original author(s) and source are credited.

\section{References}

Brandenburg, U., \& De Wit, H. (2012). Getting internationalization back on track. IAU Horizons, 17-18(3-1), 17-18.

Deardorff, D. (2012). Looking to the future: Leadership perspectives on international synthesis. The International Journal of Higher Education and Democracy, 3, 71-80.

Education, Audiovisual and Culture Executive Agency. (2012). Higher education in Kazakhstan. Retrieved from http://eacea.ec.europa.eu/tempus/participating_countries/overview/Kazakhstan. pdf.

Engberg, D., Glover, G., Rumbley, L. E., \& Altbach, P. G. (2014). The rationale for sponsoring students to undertake international study: an assessment of national student mobility scholarship programmes. The British Council.

Hayward, F. M., Ncayiyana, D. J., \& Johnson, J. E. (2003). A guide to strategic planning for African higher education institutions. Centre for Higher Education Transformation (CHET).

Heyl, J. D., \& Tullbane, J. (2012). Leadership in international higher education. In D. K. Deardorff, H. de Wit, J. D. Heyl, \& T. Adams (Eds.), The Sage handbook of international higher education (pp. 113-130). Thousand Oaks: Sage.

Hudzik, J. (2011). Comprehensive internationalization: from concept to action. Washington, DC: NAFSA: Association of International Educators.

Jiang, N., \& Carpenter, V. (2014). A case study of emerging challenges and reflections on internationalization of higher education. International Education Studies, 7(9), 56-68. 
Jones, E., \& Brown, S. (2007). Internationalising Higher Education. London: Routledge.

Jones, E., \& de Wit, H. (2012). Globalization of internationalization: Thematic and regional reflections on a traditional concept. The International Journal of Higher Education and Democracy, 3, 35-54.

Kezar, A. (2014). Higher education change and social networks: A review of research. The Journal of Higher Education, 85(1), 91-125.

Knight, J. (2004). Internationalization remodeled: Definition, approaches, and rationales. Journal of Studies in International Education, 8(1), 5-31.

Knight, J. (2013). The changing landscape of higher education internationalisation - for better or worse? Perspectives: Policy and Practice in Higher Education, 17(3), 84-90.

Koehn, P. H., Deardorff, D. K., \& Bolognese, K. D. (2011). Enhancing international research and development-project activity on university campuses: Insights from US senior international officers. Journal of Studies in International Education, 15(4), 332-350.

Leask, B. (2013). Internationalizing the curriculum in the disciplines-imagining new possibilities. Journal of Studies in International Education, 17(2), 103-118.

Lumby, J. (2012). Leading organizational culture: Issues of power and equity. Educational Management Administration \& Leadership, 40(5), 576-591.

MoES, Ministry of Education and Science of the Republic of Kazakhstan. (2007a). Laws on education of the Republic of Kazakhstan. Retrieved from http://old.edu.gov.kz/fileadmin/user_ upload/npa/zakoni/zakon_ob_obrazovanii.doc.

MoES, Ministry of Education and Science of the Republic of Kazakhstan. (2007b). Order of Acting Minister of Education and Science of Kazakhstan on December 27, 2007 No. 661 On approval of Rules for International Cooperation Realized by Educational Organizations. Retrieved from http://old.edu.gov.kz/fileadmin/user_upload/npa/podzakoni/Prikaz_No_661. doc.

MoES, Ministry of Education and Science of the Republic of Kazakhstan. (2012). Strategy for academic mobility in the Republic of Kazakhstan for 2012-2020. Retrieved from http://narickazakhstan.kz/en/implementation-of-the-bp/academic-mobility/2013-01-22-10-03-13.

Taylor, J. (2010). The management of internationalization in higher education. In F. Maringe \& N. Foskett (Eds.), Globalization and internationalization in higher education: Theoretical, strategic and management perspectives (pp. 97-107). London: Continuum.

Telegina, G., \& Schwengel, H. (2012). The Bologna process: Perspectives and implications for the Russian University. European Journal of Education, 47(1), 37-49.

The Republic of Kazakhstan. (2010). The State program of education development in the Republic of Kazakhstan. http://www.akorda.kz/en/category/gos_programmi_razvitiya. 